Old Dominion University

ODU Digital Commons

VMASC Publications

Virginia Modeling, Analysis \& Simulation Center

2015

\title{
Analysis of the Cost of Emergency Managers' Meeting Load: A Hampton Road Case-Study
}

Andrew J. Collins

Old Dominion University, acollins@odu.edu

David W. Flanagan

Old Dominion University

Barry Ezell

Old Dominion University, bezell@odu.edu

Follow this and additional works at: https://digitalcommons.odu.edu/vmasc_pubs

Part of the Emergency and Disaster Management Commons, and the Public Administration Commons

\section{Repository Citation}

Collins, Andrew J.; Flanagan, David W.; and Ezell, Barry, "Analysis of the Cost of Emergency Managers' Meeting Load: A Hampton Road Case-Study" (2015). VMASC Publications. 21.

https://digitalcommons.odu.edu/vmasc_pubs/21

\section{Original Publication Citation}

Collins, A. J., Flanagan, D. W., \& Ezell, B. (2015). Analysis of the cost of emergency managers' meeting load: A Hampton Road casestudy. Journal of Homeland Security and Emergency Management, 12(1), 169-191. doi:10.1515/jhsem-2014-0005

This Article is brought to you for free and open access by the Virginia Modeling, Analysis \& Simulation Center at ODU Digital Commons. It has been accepted for inclusion in VMASC Publications by an authorized administrator of ODU Digital Commons. For more information, please contact digitalcommons@odu.edu. 


\title{
Andrew J. Collins*, David W. Flanagan and Barry Ezell Analysis of the Cost of Emergency Managers' Meeting Load: A Hampton Road Case-study
}

\begin{abstract}
Preparation for a disaster is not something that can be done by a single organization thus there is a need for coordination between them. Meetings and joint exercises are one means of coordination used by the emergency management community. Meetings and exercises take time, including transportation of personnel and arrangements, and time is money. With limited budgets, emergency managers need to make hard decisions about how their time is allocated. This paper describes a cost model for meeting analysis and discusses a case study that looks at the holistic time spent on meetings and exercises, by personnel, for the Hampton Roads Region of Virginia. A novel way is used to display this expenditure, e.g., it is shown in terms of monetary cost instead of temporal cost. This analysis highlighted some unexpected results, i.e., the small number of personnel involved in multiple working group meetings and high level of travel costs between the HR and the state capital, Richmond. This cost model approach may provide emergency managers with better mechanisms to show their meetings costs to senior leadership.
\end{abstract}

Keywords: cost modeling; emergency management; resource management.

\section{Introduction}

Preparation for a disaster is not something that can be done by a single organization and many are involved in the process, e.g., law enforcement, transportation planners, and non-governmental organizations (NGO). It is too late to think about coordination between these organizations once a disaster happens; hence, preparation arrangements must be made in advance to ensure that they are all "on the same page." Meetings and joint exercises are one commonly accepted approach to achieve this collective understanding.

*Corresponding author: Andrew J. Collins, Old Dominion University - Virginia Modeling, Analysis and Simulation Center, Suffolk, VA, USA, e-mail: ajcollin@odu.edu

David W. Flanagan and Barry Ezell: Old Dominion University - Virginia Modeling, Analysis and Simulation Center, Suffolk, VA, USA 
Meetings and exercises take time, including transportation of personnel and organizational arrangements, and time is money. With limited budgets, emergency managers need to make hard decisions about how their time is allocated. This paper looks at the time spent on meetings and exercises, by personnel, for the Hampton Roads (HR) area of Virginia. A novel way is used to display this expenditure, i.e., it is shown in terms of monetary cost instead of temporal cost. By using this novel approach, a viewer is able to grasp an understanding of the current meeting and exercise commitments for the HR area which, the authors believe, provides insight into the coordination activities of this area. Thus, this approach as the potential to be generalized to other regions; this would allow those regions' emergency management community to gain similar insight.

There is a common perception in the HR emergency management community that their meeting and exercise load is high (Redick 2010). The impact of this perceived problem is that senior leadership time has been diluted with meetings and that, across the region, the number of man-hours lost and the associated cost, due to meetings, will have an overall impact on the mission. Given this existing current perception, HR provides a natural choice for this analysis to determine if excessive meeting loads are the problem. The findings from this study produced more questions than it answers but, the authors believe, that in raising these questions helps the emergency management community understand their current situation better and thus they are more able to choose the right management strategy to complete their mission.

The following section gives some background to why meeting requirements for emergency managers have been highlighted as a problem worthy of study. This is followed by a description of the cost model used in this analysis and the data collection mechanisms. Results from the cost model are presented and their implications are discussed. Finally, conclusions are given on the analysis and emergency management meeting requirements in general.

\section{Background}

There is a saying “all disasters are local,” which highlights emergency management is first and foremost a local responsibility (Department of Homeland Security 2013) and the importance of local emergency managers (Kayyem and Pangi 2003; Krueger et al. 2009). Though local officials have the legal responsibility for dealing with most disasters, an emergency response draws on a wide range of community, economic, and political resources (Choi 2008). 
Donald Kettl points that homeland security is about coordination (Kettl 2003). This view is echoed by Reddick (Reddick 2008) who points out that one of the most important aspects of homeland security preparedness is the sharing of information between the federal, state, and local governments. However, the National Commission on Terrorist Attacks upon the US (Kean 2011) found that a lack of information sharing was common in the emergency management community (Clayton and Haverty 2005). For there to be information sharing different groups need to interact and cooperate (Caruson and MacManus 2007; Kemp 2010). Thus, if effective coordinated community resources are going to be available in response to incidents, collaboration between the different emergency management related organizations must be built (Waugh 2006).

Meetings and joint exercises are one means to encourage collaboration and coordination of emergency management related organizations. An exercise is defined here as any one off planned event and a meeting is defined as two or more people coming together to discuss one or more topics for a fixed duration at a specified location. Meetings and joint exercises take time by emergency management personnel. Emergency management offices are taking on an increasingly larger share of the responsibility for implementing homeland security policies, in addition to traditional emergency preparedness and response functions (Krueger et al. 2009) and these new tasks also take time.

In some ways, emergency management community has been cursed by its own success (Choi 2008) as there is no public will to give them more money but emergency management operation systems are severely underfunded throughout the entire intergovernmental system (Choi 2004). Krueger et al. (2009) points out that city and county budgets are constrained by anti-property tax revolts but there is the paradoxical rising expectations of citizens for more and better services. They found that the average county Emergency Management Office budget is $\$ 37,989$ (of 204 surveyed). In a national survey of US cities, Gerber et al. (2005) shows evidence that budgetary constraints are tied to homeland security preparedness.

There is financial assistance available through grants but many communities, without proper resources to apply, miss out on these opportunities (McEntire and Dawson 2007). This is an example of an opportunity cost. As Krueger et al. points out "certain US institutions are remarkable for the disconnect between the scale at which they are expected to function and the level of government at which their daily operations are funded, organized and operated" (Krueger et al. 2009).

A balance must be struck between coordinating collaboration in a region, through meetings and exercises, and spending limited funds to achieve this. Money is the common language between these two activities and, as such, any 
discussion on meeting requirements should be placed in terms of monetary value not time, as is traditionally done. This case study shows the meeting burden of HR emergency management personnel in terms of monetary cost. Though this is a novel approach, to translate time into money, we are not the first to consider this approach.

In 1908, Arnold Bennett wrote a pamphlet entitled "how to live on $24 \mathrm{~h}$ a day" (Bennett 1908). His work was a play on popular magazine articles, at the time, which discussed how an individual might survive on limited budget, e.g., how to live on $\$ 20$ a day. By encouraging readers to perceive time as a budgeted resource like money, Bennett was able to highlight to the reader how they frivolously use their time "budget" and highlighted ways to improve their (human) condition.

The same disconnect between time and the need to budget it can be seen within our modern business environment. For example, consider the scenario where a project is behind schedule; a macho project manager might announce that their team will "work $24 \mathrm{~h}$ a day to get the job done"; they are unlikely to announce that their team will "spend $\$ 10,000$ in man-hours a day to get the job done." If it man-power booking costs of the project team is $\$ 10,000$ per day then the statements amount to the same thing but the first statement sounds more impressive than the second.

\subsection{Hampton Roads}

The HR Planning District Commission (HRPDC) and the Urban Area Working Group (UAWG) need a 10-year sustainment plan to maintain the programmatic investments made in the region as a part of the U.S. Department of Homeland Security Grants Program. In 2012, HR was removed from the Urban Area Security Initiative (UASI) Program as a tier two region. Many prominent leaders and elected officials made the case to Department of Homeland Security (DHS) to explain why HR should be returned to UASI II status. To accomplish this, HRPDC, UAWG, and the Commonwealth of Virginia required HR to continue to operate as an organized UASI. Fundamental to operating as a UASI was the implementation of a credible sustainment plan underpinned with analysis and continued diligence. In 2014, HR UASI tier two was returned. Since becoming a UASI region in 2007, some emergency managers believe they have a large meeting burden placed on them relative to the ongoing responsibility for enhancing regional resilience and preparedness, and developing integrated regional systems for prevention, protection, response, and recovery from terrorism (Redick 2010). 


\subsection{Cost without Benefit}

The method and model provided in this paper focuses on the cost of meetings and not the benefits of meetings. The goal of this approach is to provide emergency managers with insight not answers. The focus on cost, and cost alone, meant that our methodology only focused on quantitative data as opposed to qualitative data. The data collected for determining costs of the meeting where travel times, meeting times, wage and participant information. For the case study considered in this paper, this data was relatively readily available; making our approach relatively easy to implement for practitioners.

Other techniques that could have been applied to this problem include cost benefit analysis (Goodwin and Wright 1991) and analysis of opportunity costs (Durlauf and Blume 2008). Both these approaches require the determination of meeting benefits of the meetings for comparison purposes. Determining meeting benefits is problematic especially within a multiple organization environment, e.g., law enforcement and industry members. The benefits to one group, or individual, might be different from another group and publicly stating these benefits, through this analysis, might cause tensions between the groups. For example, if a meeting is stated as being essential to the host organization but only marginally important to others might result in resentment between the organizations which would be completely against the goal of building coordination amongst organizations in the first place. Attendees of the meetings are likely to know about this tension thus any survey used to collect benefit data will only provide their (politically correct) stated preferences (or benefits) and not their actual preferences. As such determining the benefit data was deemed impractical and beyond the scope of the study sponsor.

Of course, by not including the benefits of meetings means that only one part of the meeting story is shown. Thus this paper focuses on the cost and provides insight to stakeholders about the allocation of resources to meetings. It does not provide answers to what the meeting load should be but rather insight into the current meeting load situation through a holistic view of costs. French and Niculae (2005) point out this is a reasonable use of models - to provide insight and not necessarily focus on the "answers."

The cost model presented in this paper provides a holistic understanding the meeting burden on a region through the novel perceptive of monetary cost as opposed to time. In the modern age of big data, it is widely been accepted that the method of data display is as essential as the data itself when communicating information to a decision-maker (Tufte and Weise Moeller 1997; Tufte 2001). In recent years different approaches to visualize information have been popularized (McCandless 2009; Yau 2011). This paper focuses on the presentation of monetary 
cost to aid the decision-makers understanding. The authors have taken great care, understanding that the use of rhetoric is subjective and has the potential to be manipulated by visualizations (Kostelnick 2008; Collins and Knowles Ball 2013) and statistics (Huff 1954).

\section{Cost Model}

"The only real voyage of discovery consists not in seeking new landscapes but in having new eyes."-Marcel Proust (1871-1922)

To analyze the meeting requirements of the HR emergency management organizations, a cost model was developed. The methodology to achieve this was split into three tasks:

1. collect information about yearly meeting and exercise demand for HR emergency managers;

2. construct a cost model for those meetings and exercises. Cost is given in both time and financial requirement; and

3. analyze the cost information and present interesting observations and insights.

The meeting information provided here is given in time and monetary cost; by giving the meeting information in this way, it is hoped that decision-makers will have "new eyes" to look at the problem and thus aid them in understanding the current situation of meeting and exercise requirements for the HR region.

\subsection{Data Collection}

The region holds approximately 286 meetings per year on HR emergency management matters. This figure includes approximately 30 meetings associated with four exercises. We had 2 years' worth of exercise data thus 315 meetings were considered in total over 2011 and 2012. Most meetings were associated with a particular working group which met frequently during the year. For example, Hampton Roads Inmate Evacuation Planning (HRIEP) working group meets every month for approximately $2 \mathrm{~h}$. There were 22 working groups identified in this study. Further examples of the working groups include Hampton Roads Regional Catastrophic Planning Team (HRRCPT), Hampton Roads Hurricane Evacuation Working group Meeting (HRHEW), Metropolitan Medical Response Service (MMRS) Over- 
sight Committee, and Area Maritime Security working group. A complete list of working groups and exercise data can be found in Appendix A. Though other meetings occurred, both formal and informal, these working groups were deemed adequate to complete this analysis by members of Hampton Roads Planning District Commission (HRPDC) because (1) they represented the mandated meetings required by the region and (2) meeting/minute data was available for analysis. There were three meeting working groups that were not used for analysis due major incompletions in their datasets.

Even the most complete meeting group datasets contained missing data. This missing data was mainly information about the attendees. For our analysis, attendee's annual wage and their home or normal business location needed to be known. This information was used to determine the travel-times to-andfrom meetings and monetary cost of the meetings; travel-time cost where given in terms of individual attendees per hour wage rate and the standard Virginia state per diem travel rate ( $\$ 0.565$ per mile).

The required meeting information was location, duration and frequency. Using this information, combined with the attendees per hour wage rate information, the cost per meeting, in terms of attendees' wages, was determined. Overhead costs, e.g., cost of meeting rooms, refreshments, etc. where not included.

\subsection{Location Information}

The location information was required to determine the travel costs of attendees to the meetings/exercises. The locations of all meetings and exercises were supplied; however, locations of attendees were not.

Attendee's locations were found through internet searches, using sources like LinkedIn accounts, company websites, area codes from phone numbers, white pages and/or other appropriate websites. There was no guarantee that all the attendee information that was collected was up-to-date or even correct. When there were multiple possibilities for an individual's location, locations in the HR region where chosen over any other possible locations.

To make the analysis easier, all locations in one city where amalgamated to one central city location. There were a few accepts to this, e.g., locations at military bases, HRPDC, Cox Communications and Virginia Natural Gas. Even though this amalgamation of city locations does affect the accuracy of the results, this was deemed acceptable for our analysis given the other approximations used, e.g., exact meeting length, attendee's actual attendance, etc.

Once the location data for meetings and attendees was complete, it was possible to determine travel time and distance for the attendee's traveling to and from 
a meeting location. This information was found using Google maps (maps.google. com). It was assumed that there were no travel delays from incidents or rush-hour traffic. The travel distance was used to determine the travel costs of the attendee at $\$ 0.565$ per mile; ${ }^{1}$ it was assumed that all attendees travel by their own car. The travel time was used to determine the wage cost of an attendee traveling to and fro from the meeting. When multiple locations were given for a meeting group, we assumed that the group's meetings where evenly split across these locations.

\subsection{Wage Information}

The Richmond Times-dispatch Online ${ }^{2}$ for state employees and The Virginia Pilot ${ }^{3}$ Online for HR city employees were the two main sources for determining the wage information of the attendees. The Richmond Times-dispatch database was from 2011 and only contained employees with a salary over the state employee average of $\$ 52,559$. The Virginia Pilot database was also from 2011 and categorized employees by job title, as opposed to name. From the two databases, only about $12 \%$ of the attendee's wages were discovered. The remaining attendees were assumed to have the state employee average salary of $\$ 53,000$; this figure was deemed a "low ball" estimate because it would be expected that highly qualified (and paid) professionals where those that attended the meetings/exercise. The wage that an individual gets is not the only cost that company pays to keep them on staff; there is also fringe benefits (pension, medical insurance, etc.) and indirect cost (office heating and rental, administrative staff, managerial oversight cost, etc.). It was assumed that these values take the state average of $30 \%$ for fringe benefits and $53 \%$ for indirect costs which is in-line with many government grant arrangements. Given the lack of wage information for the attendees, these average salary estimates formed the basis of our sensitivity analysis.

All meeting attendees were included in this analysis. The argument for keeping private sector personnel in the list is due to the importance they play in emergency management (Kapucu et al. 2010). The National Strategy for the Physical Protection of Critical Infrastructures and Key Assets (2003) recognizes that the "private sector generally remains the first line of defense for its own facilities." Thus our total cost is the overall burden to the HR region, not just the local government. Indirectly, the cost of the participants from private groups is still

1 This is the standard per diem rate for Virginia state employees.

$2 \mathrm{http}$ //datacenter.timesdispatch.com/databases/salaries-virginia-state-employees-2011-results/.

$3 \mathrm{http}: / /$ hamptonroads.com/newsdata/salaries. 
paid for by the community via the charges leveraged by the private groups on the community, e.g., power companies, etc. Thus the costs provided by the model include both direct cost, e.g., taxes, and indirect cost, e.g., company charges, on the local community. There are several reasons a private group might attend a emergency management meetings: out of a social responsibility, the "price of doing business" in that region or need to be there to ensure their best interests are taking care of.

\subsection{Missing Data}

The meeting data provided by HR was incomplete for our intended analysis. Some data was universally absent, e.g., wage information, and some was only missing from certain meetings, e.g., meeting frequency. Assumptions had to be made to fill in the missing data gaps and a generalized list of assumptions can be found in Table 1. When no information was given about a meeting's location it was assumed to be the same as previous meetings in that working group, if possible. When no information was given about the meetings duration, it was assumed to be $2 \mathrm{~h}$ long, which is the median of the durations of the meetings that were known about.

The analysis method and data gaps meant that several assumptions needed to be made within the analysis. Where possible, an assumption was chosen that would reduce the overall cost. As assumption had to be made it is unlikely that all the data used in our analysis is correct and the monetary values given in this paper are an underestimation of the true cost of the meetings and exercises.

The study began with a grand attempt to identify all meetings, associated task, purpose, attendees by name and affiliation, meeting cycle, inputs, outputs, products, and linkages to regional risk impact. However, not all information was available and the information provided provides a good baseline of overall regional burden. This analysis has made no attempt to determine if any meetings/ exercise should be removed from (or added to) the HR calendar its sole purpose is to act as a catalyst to a discussion on the meeting burden on emergency managers.

\subsection{Overview of the Cost Model}

Using the information collected above, a cost was determined for each meeting in terms of attendees' wages. As mentioned above, this does not include the overhead costs of a meeting, e.g., room maintenance cost, equipment costs, refreshments, etc. This cost was determined by the following model: 


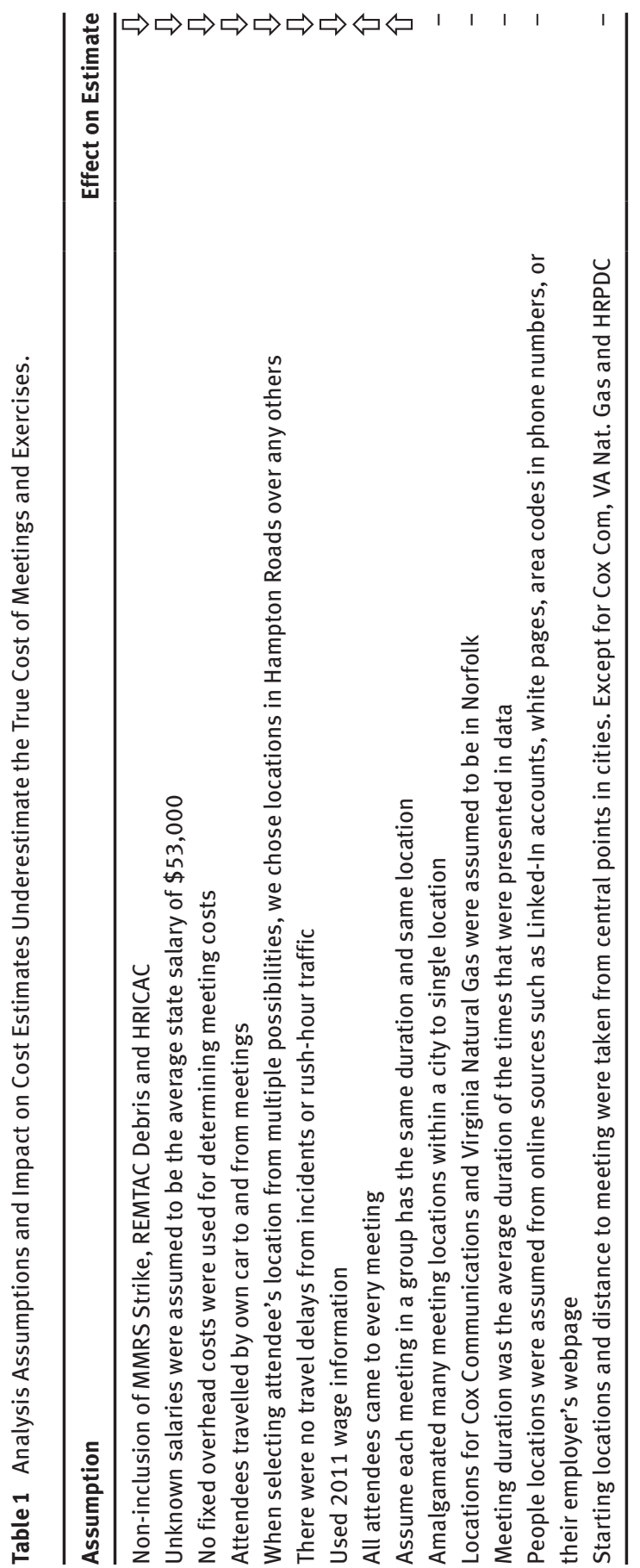




$$
C(m)=\sum_{a \in A} w(a) I_{m}(a)(2 t(L(a), L(m))+t(m))+\sum_{a \in A} 0.565 \times 2 \times I_{m}(a) d(L(a), L(m))
$$

$C(m)$ is the estimated cost of meeting " $m$ " in dollars. For each attendee " $a$," their hourly wage rate is $w(a)$ (including fringe and indirect costs) and their attendance to the meeting is determine by the indicator function $I_{m}($.) which equals one if the participant was at the meeting and zero otherwise. " $A$ " is the set of all attendees. The location of meetings and participants is given by $L($.) and the distance is determined by $d($., .). The duration function is overloaded to determine both the duration of the meeting $t$.) and the duration of travel $t(.$, .). The per diem for travel is given by $\$ 0.565$. The working group cost was determined by multiplying the individual cost of a single meeting by frequency of meetings (i.e., meetings per year) if information about each individual meeting in the working group was not given.

\subsection{Example of the Cost Model Application}

A simple example is given here to help the reader understand the application of cost model formula. Consider a scenario which involves a single $3 \mathrm{~h}$ meeting of 10 individuals $\left(a_{1}, a_{2}, \ldots, a_{10}\right)$ all of whom are paid exacting $\$ 100$ per hour including fringe and indirect costs to the employers. Let us assume that the meeting takes place in city A, which is the home organization of five of the individuals. The other five individuals are based in city B, which is 100 miles from city A, which takes $2 \mathrm{~h}$ to drive. Thus the cost for the attendees based in city A will be:

$$
\$ 1500=\sum_{a \in\left\{a_{1}, a_{2}, \ldots, a_{5}\right\}} \$ 100 \times 1 \times(2 \times 0+3)+\sum_{a \in\left\{a_{1}, a_{2}, \ldots, a_{5}\right\}} \$ 0.565 \times 2 \times 1 \times 0 .
$$

The cost formula is split into two parts: time and distance. The first part looks at cost (in terms of hourly wage) of time spent relating to this meeting. Since the attendees are based in City A there is no cost associated with the time it takes them to travel. They all do spend $3 \mathrm{~h}$ at the meeting so there is a cost of $\$ 300$ per attendee. The distance part of the formula only refers to distance travel so for those attendees based at City A, there is no travel cost. The cost for the attendees coming from city B will be:

$$
4065=\sum_{a \in\left\{a_{6}, a_{7}, \ldots, a_{10}\right\}} 100 \times 1 \times(2 \times 2+3)+\sum_{a \in\left\{a_{6}, a_{7}, \ldots, a_{10}\right\}} \$ 0.565 \times 2 \times 1 \times 100 .
$$

In this instance there is a travel cost in both terms of time and distance. Traveling to the meeting take $2 \mathrm{~h}$, each way, so there is an extra $\$ 400$ in travel cost due 
to each attendee's time spent travelling. There is also a per diem travel expense of $\$ 0.565$ per mile per attendee. As the distance between the cities is 100 miles then a total of 200 miles will be travel thus there is a per diem travel cost of $\$ 1130$. Thus the model determines the total cost for this meeting will be $\$ 5565$, of which $\$ 2565$ is spent on travel. If this meeting was part of group then this number would be included in the total cost for that meeting group.

\section{Results}

The HR region spends approximately \$2.1 M annually on emergency management meetings and approximately 34,000 man-hours are annually spent at meetings including transportation of personnel to-and-from them. The amount seems high when compared to Virginia FY2012 allocation from U.S. Department of Homeland Security was $\$ 5.4 \mathrm{M}$ (note that our figure does include the cost to private companies). One of the most interesting results we found was that there seems to be very little overlap in personnel attending the 315 meetings, which was unexpected. There were 615 attendees and 502 individuals recorded with only 77 people involved in overlap. Of those that overlapped, only three people attended five different groups each. Thus these three individuals are considered critical in sharing information across the meeting groups. This might indicate that more overlap of personnel is required to satisfy the regions need for better coordination among the relevant organizations. Sensitivity analysis of the assumed average wage value indicated that the total cost of meetings could be as high as \$3.9 M per year.

The locations with the largest number of attendees were Virginia Beach (72), Norfolk (71), Richmond (59) and Chesapeake (57). Richmond is the state capital and is outside the HR region. Some attendees were coming as far as Washington, D.C. Number of attendees at the meetings ranged from 6 to 92. Associated costs estimated at $\$ 1000$ to $\$ 29,300$ per meeting including travel with travel cost are estimated at $\$ 400$ to $\$ 15,000$ per meeting.

Table 2 shows the average total meeting expenses, which are approximately \$2.1 M per year. This means that the region spent approximately two million in attendee's wages for the attendees to attend and travel to the meetings.

It is noticeable that, per year, the amount of time and money spent on exercises (and their preparation) is substantially less than the amount spent on general group meetings. Another noticeable feature of Table 2 is that the split between travel expenses and actual meeting time expenses are approximately the same. For the general group meetings, more is spent on travel. For exercises, more is spent on the actual meeting. This difference occurs because exercise 
Table 2 Descriptive Statistics from the Cost Model Results Using Averaged Data from 2011 and 2012.

\begin{tabular}{|c|c|c|c|c|c|c|}
\hline & \multirow{2}{*}{ Attendees } & \multirow{2}{*}{ Work Groups } & \multicolumn{4}{|c|}{ Annual Totals } \\
\hline & & & Man-hours & Travel Cost & Meeting Cost & Total Cost \\
\hline Meetings & 615 & 22 & 28,800 & $\$ 946,000$ & $\$ 892,000$ & $\$ 1,838,000$ \\
\hline Exercise & 906 & 4 & 5000 & $\$ 113,000$ & $\$ 164,000$ & $\$ 277,000$ \\
\hline Total & 1521 & 26 & 33,800 & $\$ 1,059,000$ & $\$ 1,056,000$ & $\$ 2,115,000$ \\
\hline
\end{tabular}

tends to be longer than normal group meetings, hence the ratio of time spent traveling exercise is lower.

\subsection{Graphical Analysis of the Regions Travel}

Decision-makers can be "turned off" by the display of statistics and other numerical data (Collins and Knowles Ball 2013) and, as such, it is important to try and display the data in a user friendly way. Graphics are one approach to achieve this and they provide rapid accessibility to the results from the analysis. To exemplify this point, two graphics have been produced to display the travel requirements in the region. The first looks at travel outside of HR to HR risk management meetings (Figure 1) and the second looks at travel within the HR region (Figure 2).

Figure 1 depicts the travel of attendees from outside the HR regions to meetings inside the region. The red dots indicate location of emergency management meetings in HR. The size of the dot represents the amount of meetings held in that location as well as the number of people traveling to that location. The green marks are the cities that attendees come from to attend meetings in HR. The connecting lines indicate the number of people traveling to meetings. The thin lines represent a number 10 or less while the thickest lines represent higher numbers ranging from 15 to 60 . The lines show straight line distances, as opposed to actual travel routes for aesthetic reason. The graphic does not show all the attendees for the year. For example, if one person came to only one meeting, they were left out of the diagram; this was done for aesthetic reasons.

A noticeable feature about Figure 1 is the thickness of the line coming from Richmond to Chesapeake. This indicates that there are many individuals coming from Richmond to Chesapeake, for meetings, throughout the year. The large red dot at Chesapeake indicates that a largest number of meetings are 


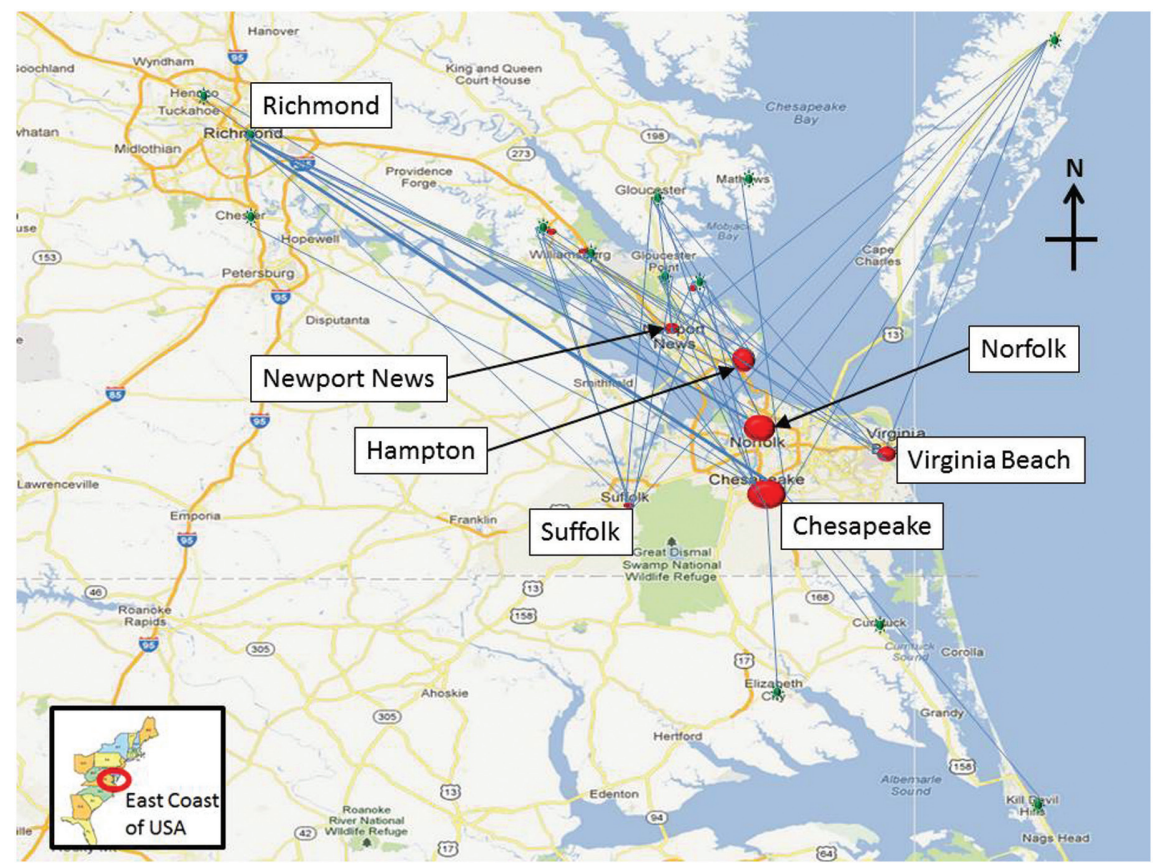

Figure 1 Snapshot of Travel of Attendees from Outside the Hampton Roads Region (green) to the Meetings within Hampton Roads (red).

held there; Norfolk follows with the second largest. What is interesting about this figure is that Chesapeake is one of the furthest points, from Richmond, for having meeting yet the majority of meetings involving Richmond personnel happen there.

Figure 2 shows the traveling of attendees within the HR region. Locations are given at the city centers with the exception of Virginia Beach, where the oceanfront was used for aesthetic reasons. For each city a starting location is given (green) and a meeting is location is given (red); these locations are slight perturbed from each other for clarity reasons.

Norfolk and Virginia Beach have the highest number of people traveling in the area. With Chesapeake holding the most meetings and having the most people travel to attend. The other cities have very few meetings and have only small amounts of people traveling to those localities. Thus this figure shows no significant issues with travel within the HR areas and that Chesapeake is, once again, the hub for Emergency Management activities. 


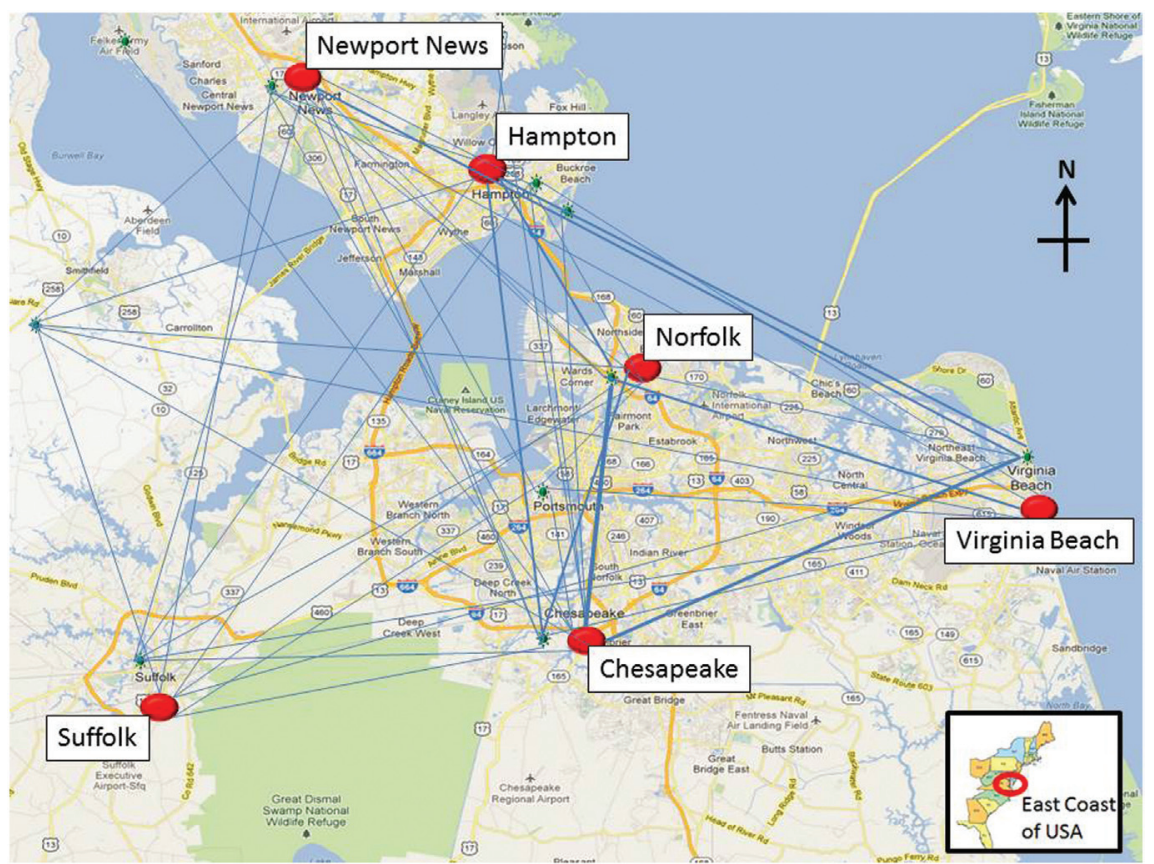

Figure 2 Snapshot of Travel of Attendees from Inside the Hampton Roads Region (green) to the Meetings within Hampton Roads (red).

\section{Discussion}

This paper focuses on displaying the cost of emergency management meetings in a holistic and novel way. Benefits of having these meetings are not discussed nor are opportunity costs of what the meeting time could have been used for as both are extremely difficult to determine, if not intangible. Thus we focused on want we could measure: time spent on meetings and exercises. Our approach shows a picture of meetings in a region and thus allows the decision-maker to gain insights of these meeting requirements. In our case-study, there were two insights that were not apparent before the analysis. The results indicate that a lot of meeting expenditure and time goes on transportation between Richmond and Chesapeake. Second is the apparent lack of attendee overlap between meetings which indicates that there are a few key people that provide synergy across all the meetings.

By providing insight to the meeting situation of a region allows a decision maker to address these potential problems. For example, possible solutions to reducing this expenditure could include moving HRPDC, where a large number of 
meetings are held, to Newport News or through the use of Video Tele Conferencing (VTC). About half of all the man-hours allocated to meetings are the travel times and thus decreasing the frequency of the meetings would be a cost-saving measure even if that meant the meetings themselves had longer durations. However, the lack of attendee overlap between meetings indicates that there may be not enough meetings to ensure coordination amongst the HR' emergency management community. This lack of overlap of attendees is something worthy of further discussion and, at a minimum, these key personnel should be recognized for their overall perspective of the HR risk management situation.

The results from our case study analysis indicate that half of our expected meeting costs are travel costs which includes both people's time traveling and per diem for travel. However, many individual organizations only consider travel cost in terms of travel per diem which is significantly small faction of the total travel cost considered in this analysis. By only considering this fraction, organizations are not taking into account the true cost of meeting travel. The results emphasize the importance in assessing the cost of meetings from a holistic perspective that includes both a broad definition of attendee costs (e.g., including wage costs) and an aggregation of the costs across all attendees.

The purpose of giving the meetings in monetary cost terms, in this approach to analysis, is that it is easier to sale a monetary saving than time saving, i.e., it is easier to report that you wish to save " $\mathrm{X}$ " dollars in meeting/exercises requirements than "Y" hours of emergency managers time. Obviously, the monetary value is not explicitly saved because wages still need to be paid but by not attending excessive meetings, the emergency managers are able to spend time on "their day job" which might have otherwise been passed on to other team member resulting in more staff at the emergency manager office location; this is an example of an opportunity cost. The monetary value given includes the costs for individuals from private companies, e.g., power companies, and it is up to those companies to determine how best they should allocate their resources.

The challenge to a manager of interpreting these new cost data is significant, however. Future research needs to explore the relationship of escalating cost to benefit. It may be, for example, that benefit increases even faster than costs as more attendees participate in meetings. Of course, the opposite is possible as well, but the present study provides a basis for better calculating the cost side of the equation and setting the stage for these even more interesting research questions.

This paper has made no attempt to determine if any meetings/exercise should be removed from the HR calendar. Even if we were able to evaluate the purpose of any of the meetings against the HR risk management mission it is likely that we would have missed many of the actual unstated purposes of the meeting. These unstated purposes of a meeting might be to disseminate of information around 
different agencies, the open evaluation of ideas by attendees, etc. Thus given the subjective judgment involved in any such decisions about removing meetings, it is left to HR emergency managers and it is hoped that the research presented in this paper will act as a catalyst to this discussion.

This analysis has also not discussed the effectiveness of meetings and these were deemed beyond the scope for this work. In a survey of city managers, Reddick (2008) discovers that it was not very common to use performance systems to gain accountability of the level of collaboration that occurred. However, the city managers did believe that a high level of collaboration among government officials was occurring. Given that the information shared by emergency mangers is often anecdotal and incomplete (Canton 2007), it would be hard to determine any performance measures. Given that the complete actual benefit of meetings, especially those intangible benefits, cannot be determined is the reason that cost is only factor considered in this paper. Thus, no discussion is offered there on either the benefit of meetings or the opportunity cost of not having meetings.

Meetings are only one way that better collaboration/coordination, amongst emergency management organizations, can be achieved. Thus focusing purely on meetings might not be best way to address this problem. For example, some of the collaboration issues discussed in this paper might be overcome with changes to the management techniques used by emergency managers. This is a popular idea in the literature and several approaches have been suggested: Business Continuity (Shaw and Harrald 2006), Matrix Management (Clayton and Haverty 2005), contingent coordination (Kettl 2013), adaptive management (Reddick 2008), strategic management (Choi 2008), and Regionalism (Caruson and MacManus 2007). However, Reddick's (2008) survey of city managers found that they believe that their city has a high level capacity to coordinate and control homeland security preparedness so the city managers are unlikely to see the need for a different management style.

\subsection{Budgets}

The cost of recovering for disaster might be high but the value placed on preparedness is ranked low. This occurs because emergency management has been a lowpriority political issue (Briechle 1999), only getting on the public agenda during or immediately after a disaster. For example, Choctaw County, Alabama got \$84.41 per capita after hurricane Georges disaster (Krueger et al. 2009); the average found Emergency Management Office budget per capita was \$1.71. More importantly, it is unlikely that emergency management budgets are likely to increase due to emergency management programs not having strong political constituencies to support effective action and encourage larger budget allocations (Choi 2008). In 
a survey of city officials, Baldassare and Hoene (2002) found that "only around one quarter of respondents believed that there was a likelihood of city residents supporting additional local taxes to fund homeland security preparedness, while $58 \%$ believed that this is unlikely." Thus when faced with increased responsibilities, emergency managers might have no choice but to decrease the number of meeting that are held, no matter how beneficial they are. The approach outline in this paper might aid decision-makers in making these hard budgetary decisions and, maybe, allowing emergency managers a means to communicate some of these issues to politicians and other high-level decision-makers.

The cost of meetings is only one part of the larger question of funding allocation of emergency management. There are larger questions that need to be addressed such as: (1) how much should EM offices be funded overall, (2) how should the money be allocated within the office between office-based work and non-office-based work, (3) how should money be allocated between meetings vs. exercises; (4) how should money be allocated to travel vs. wage costs of attending meetings, (5) do different types of meetings deserve different allocations; and (6) should the focus be on doing office-based work more efficiently rather than cutting meetings? These are distinct political and managerial questions are implicitly raised by the analysis but we have made no attempt to address them here as we believe it is beyond the scope of this paper.

\section{Conclusions}

This paper outlines an approach to help decision-makers make an informed evaluation of their emergency management meeting requirements within a region. The approach was to construct a holistic cost model of meeting requirements in a region which focuses on monetary cost and not temporal cost. By implementing this approach a snap-shot of the meeting requirements is given in an understandable language of decision-makers, e.g., money. To demonstrate this benefit, a case-study of HR was used. To construct a cost model of such a large region, many assumptions had to be made because of the limited availability of data, e.g., wage information and travel conditions at the time of the meetings. However, these assumptions were chosen to give the most modest estimate of meeting cost.

The HR region spends approximately \$2.1 M annually and 34,000 man-hours annually on emergency management meetings including exercises and transportation of personnel to them. These results are based of 22 working group that meet frequently during a year and four exercises per year. These meetings allow for the coordination between emergency management related organizations. However, with shrinking budgets and greater responsibilities, all these meeting might 
not be possible in the future. The analysis provided in this paper highlights the resources requirements of these meeting in terms of monetary value. Using our novel approach of displaying meeting costs in terms of monetary value, instead of time, may provide emergency managers with better mechanisms to show their cost savings, e.g., it sounds better to say that you saved $\$ 15,000$ from reducing the number of meetings as opposed to saying you saved 400 man-hours. Given the highly publicized resource allocation of Emergency Management Offices (Backoff et al.1993), reducing spending might provide emergency managers the rhetorical tools needed to make the strategic management decisions to fulfil their increasing mission burden.

This holistic perspective from our cost model means that the cost of a meeting is calculated in terms of all attendees and not just an individual or organizations involvement thus a meeting cost is shown in its entirety to region. Thus an individual attendee might not see their travel burden as having much impact on the cost of the meeting but when aggregated, the travel cost could play a significant part of the meeting's overall costs. Though understanding the cost of meetings in the holistic way provides decision-makers with a new perspective to evaluate their meeting burden.

The approach of the paper is solely focused on cost of meetings and does not consider their benefit or the opportunity cost of not having a meeting with the exception of reduced transportation time. Though analysis of these aspects would be interesting there was little or no data available to complete this due the intangible nature of the data required. As pointed out by Caruson and MacManus (2007), it is unlikely that any approach will benefit all involved in homeland security preparedness and the method highlighted in this paper is no exception. However, the authors believe the approach and results will help emergency managers think about the limited resources problem and how meetings might be more efficient.

Further studies could include analysis of the opportunity cost of conducting meetings. Though the information required to do this analysis would be difficult to obtain a survey instrument could be used to obtain information on the opportunities lost due to the current meeting burden of emergency managers. This information collected would be incomplete as it assumes that interviewees would be aware of the opportunities lost due to attending meetings and exercises. However, as mentioned earlier in the paper, the collection of meeting benefit information could have inter-organization political ramifications, as meeting preferences will be revealed amongst the stakeholder organizations, and any data collection should be conducted with this potential problem in mind. Also, given the sheer number of attendees, this survey would only be able to cover a small sample of them. The survey instrument could also be used to give a more rigorous determination of the perception of meeting load within a region beyond the anecdotal evidence given in this paper. 


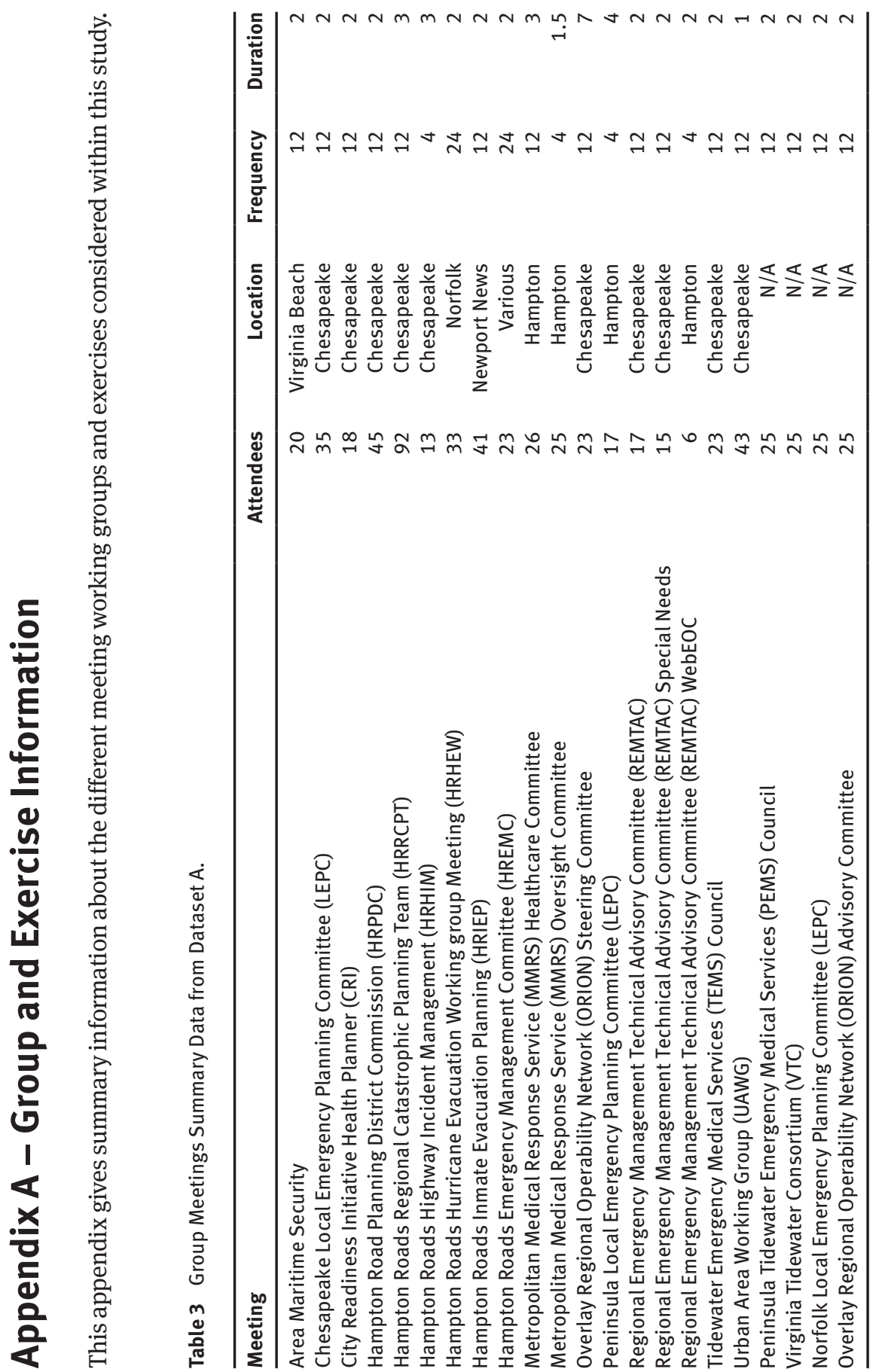




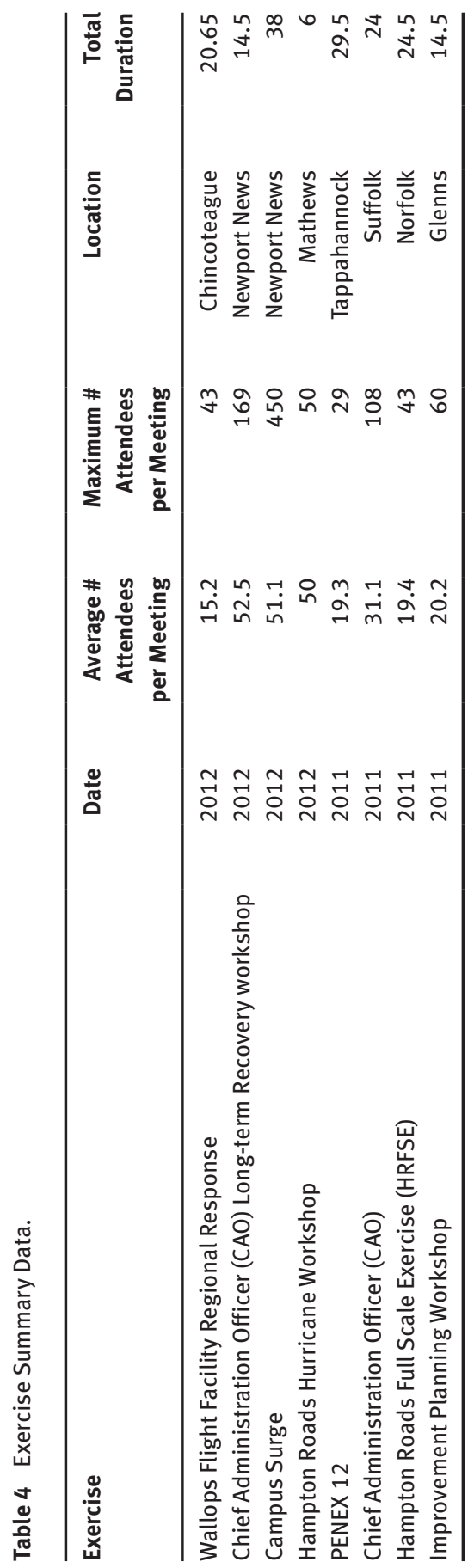




\section{References}

Backoff, Robert, Barton Wechsler and Robert E. Crew Jr. (1993) "The Challenge of Strategic Management in Local Government,” Public Administration Quarterly, 17(2):127-144.

Baldassare, Mark and Christopher Hoene (2002) Coping with Homeland Security: Perceptions of City Officials in California and the United States. San Francisco, CA: Public Policy Institute of California.

Bennett, Arnold (1908) How to Live on 24 Hours a Day. London: The New Age Press.

Briechle, Kendra J. International City County Management Association (1999) Smart Growth for Local Governments. Washington, DC: ICMA.

Bush, George W. (2003) The National Strategy for the Physical Protection of Critical Infrastructures and Key Assets. Ft. Belvoir, VA: Defense Technical Information Center (DTIC).

Canton, Lucien G. (2007) Emergency Management: Concepts and Strategies for Effective Programs. New Jersey: Wiley-InterScience.

Caruson, K. and S. A. MacManus (2007) "Designing Homeland Security Policy within a Regional Structure: A Needs Assessment of Local Security Concerns," Journal of Homeland Security and Emergency Management, 4(2).

Choi, Sang Ok (2004) “Emergency Management Growth in the State of Florida," State and Local Government Review, 36(3):212-226.

Choi, S. O. (2008) “Emergency Management: Implications From a Strategic Management Perspective," Journal of Homeland Security and Emergency Management, 5(1).

Clayton, Ross and Dan M. Haverty (2005) "Modernizing Homeland Defense and Security," Journal of Homeland Security and Emergency Management, 2(1):7.

Collins, Andrew J. and D'an Knowles Ball (2013) “Philosophical and Theoretic Underpinnings of Simulation Visualization Rhetoric and Their Practical Implications.” In: (Andreas Tolk, ed.) Ontology, Epistemology, and Teleology for Modeling and Simulation. Heidelberg: Wiley, pp. 173-191.

Department of Homeland Security (2013) National Response Framework. Washington DC: Department of Homeland Security.

Durlauf, Steven N. and Lawrence E. Blume (2008) “The New Palgrave Dictionary of Economics.” Basingstoke, UK: Palgrave Macmillan.

French, Simon and Carmen Niculae (2005) "Believe in the Model: Mishandle the Emergency," Journal of Homeland Security and Emergency Management, 2(1).

Gerber, Brian J., David B. Cohen, Brian Cannon, Dennis Patterson and Kendra Stewart (2005) "On the Front Line American Cities and the Challenge of Homeland Security Preparedness," Urban Affairs Review, 41(2):182-210.

Goodwin, Paul and George Wright (1991) Decision Analysis for Management Judgment. 3rd ed. Chichester, UK: Wiley.

Huff, Darrell (1954) How to Lie with Statistics. New York: W. W. Norton \& Company.

Kapucu, N., T. Bryer, V. Garayev and T. Arslan (2010) “Interorganizational Network Coordination under Stress Caused by Repeated Threats of Disasters," Journal of Homeland Security and Emergency Management, 7(1).

Kayyem, Juliette N., and Robyn L. Pangi (2003) First to Arrive: State and Local Responses to Terrorism. Cambridge, MA: MIT Press.

Kean, Thomas (2011) The 9/11 Commission Report: Final Report of the National Commission on Terrorist Attacks Upon the United States. New York: Government Printing Office. 
Kemp, Roger L. (2010) Homeland Security: Best Practices for Local Government. Washington, DC: International City/County Management Association.

Kettl, Donald F. (2003) "Contingent Coordination Practical and Theoretical Puzzles for Homeland Security," The American Review of Public Administration, 33(3):253-277.

Kettl, Donald F. (2013) System Under Stress: Homeland Security and American Politics. 3rd ed. Thousand Oaks, CA: CQ Press.

Kostelnick, C. (2008) "The Visual Rhetoric of Data Displays: The Conundrum of Clarity," Professional Communication, IEEE Transactions, 51(1):116-130.

Krueger, S., E. Jennings and J. M. Kendra (2009) "Local Emergency Management Funding: An Evaluation of County Budgets," Journal of Homeland Security and Emergency Management, 6(1).

McCandless, David (2009) The Visual Miscellaneum: A Colorful Guide to the World's Most Consequential Trivia. 1st ed. New York, NY: Harper Design.

McEntire, David A. and Gregg Dawson. (2007) "The Intergovernmental Context in Emergency Management: Principles and Practice for Local Government.” In: (William L. Waugh and Kathleen J. Tierney, eds.) Emergency Management: Principles and Practice for Local Government. Washington, DC: ICMA Press, pp. 57-70.

Reddick, C. G. (2008) “Collaboration and Homeland Security Preparedness: A Survey of US City Managers," Journal of Homeland Security and Emergency Management, 5(1).

Redick, James A. (2010) Regional Disaster Planning: Observations and Recommendations, A Case Study Of Hampton Roads. City of Virginia Beach, Office of Emergency Management.

Shaw, G. L. and J. R. Harrald (2006) "The Core Competencies Required of Executive Level Business Crisis and Continuity Managers - The Results," Journal of Homeland Security and Emergency Management, 3(1).

Tufte, Edward R. (2001) The Visual Display of Quantitative Information. 2nd ed. Cheshire, CT: Graphics Press.

Tufte, Edward R. and E. Weise Moeller (1997) Visual Explanations: Images and Quantities, Evidence and Narrative, Vol. 36. Cheshire, CT: Graphics Press.

Waugh, William L. (2006) "The Political Costs of Failure in the Katrina and Rita Disasters," The Annals of the American Academy of Political and Social Science, 604(1):10-25.

Yau, Nathan (2011) Visualize This: The FlowingData Guide to Design, Visualization, and Statistics. Indianapolis: Wiley. 